\title{
Application of indocyanine green video angiography in surgical treatment of intracranial aneurysms
}

\author{
Aplicação da angiografia intraoperatória com indocianina verde no tratamento cirúrgico \\ de aneurismas cerebrais
}

Felix Hendrik Pahl',2, Matheus Fernandes de Oliveira',2, Roger Schmidt Brock², José Erasmo Dal'Col Lucio ${ }^{2}$

\begin{abstract}
Indocyanine green (ICG) video angiography has been used for several medical indications in the last decades. It allows a real time evaluation of vascular structures during the surgery. This study describes the surgical results of a senior vascular neurosurgeon. We retrospectively searched our database for all aneurysm cases treated with the aid of intraoperative ICG from 2009 to 2014 . A total of 61 aneurysms in 56 patients were surgically clipped using intraoperative ICG. Clip reposition after ICG happened in 2 patients (3.2\%). Generally, highly variable clip adjustment rates of 2\%-38\% following ICG have been reported since the introduction of this imaging technique. The application of ICG in vascular neurosurgery is still an emerging challenge. It is an adjunctive strategy which facilitates aneurismal evaluation and treatment in experienced hands. Nevertheless, a qualified vascular neurosurgeon is still the most important component of a high quality work.
\end{abstract}

Keywords: aneurysm, treatment, surgery, indocyanine green.

RESUMO

A angiografia intraoperatória com indocianina verde (ICG) já foi aplicada em diversas situações clínicas por vários anos. 0 ICG permite avaliação em tempo real de estruturas vasculares durante a cirurgia. Este artigo descreve os resultados cirúrgicos do autor sênior. Avaliamos retrospectivamente os casos de aneurismas intracranianos operados de 2009 a 2014. Um total de 61 aneurismas em 56 pacientes foram operados com ICG. O reposicionamento do clip ocorreu em 2 casos (3.2\%). Geralmente, taxas variáveis de reposicionamento do clip têm sido descritas (2\%-38\%). A aplicação de ICG na neurocirurgia vascular ainda é um desafio crescente. É um artifício que auxilia na avaliação e tratamento de aneurismas intracranianos em mãos experientes. No entanto, um neurocirurgião vascular continua sendo o principal componente de um resultado cirúrgico de alto nível.

Palavras-chave: aneurisma, tratamento, cirurgia, indocianina verde.

Indocyanine green (ICG) video angiography has been used for several medical indications in the last decades. It allows a real time evaluation of vascular structures during the surgery ${ }^{1,2,3,4,5}$.

Indocyanine green dye was developed for near-infrared photography by the Kodak Research Laboratories in 1955 and was already approved for clinical use in 1956. However, it was used for angiography in the 60's and for retinal angiography in the 70 's. The principle of fluorescence imaging used in ICG is simple: illuminate the tissue of interest with light at the excitation wavelength $(800 \mathrm{~nm})$ while observing it at longer emission wavelengths (over $800 \mathrm{~nm})^{1,2,3,4,5}$.
Neurosurgery is ideal for ICG because operations are already done using microscope (and camera), and because the blood vessels located on the brain surface are exposed and thus can be seen more or less directly by visual means. Thus, ICG applied in vascular neurosurgical procedures has emerged as a valuable option to assess intraoperatively details of aneurysmal clipping ${ }^{4,5,6.6}$

Although with increasing reports of ICG application, there are still some points to be discussed. Additionally, Brazilian literature has no publication about such theme to the best of our knowledge. We report below the first Brazilian experience with application of ICG in the treatment of intracranial aneurysms ${ }^{4,5,6}$.

'Iamspe, Hospital do Servidor Público Estadual de São Paulo, Departamento de Neurocirurgia, Sao Paulo SP, Brazil;

${ }^{2}$ DFV Neuro, Sao Paulo SP, Brazil.

Correspondence: Felix Hendrik Pahl; Al Franca, 432-apt. 31; 01422-002 Sao Paulo SP, Brasil; E-mail:fpahl@globo.com

Conflict of interest: There is no conflict of interest to declare.

Received 22 December 2014; Received in final form 26 February 2015; Accepted 18 March 2015. 


\section{METHOD}

This study describes the surgical results of a senior vascular neurosurgeon (Pahl FH). We retrospectively searched our database for all aneurysm cases treated with the aid of intraoperative ICG from 2009 to 2014. A total of 61 aneurysms in 56 patients were surgically clipped using intraoperative ICG. We did not apply routine intra operative subtraction angiography. Angiography is done in an outward basis.

Indications for neurosurgical treatment of aneurysms were unruptured aneurysms with $5 \mathrm{~mm}$ or above, symptomatic aneurysms and/or associated subarachnoid hemorrhage (SAH).

Technical principles of ICG have been described in detail by Raabe et al 5 . A bolus of $25 \mathrm{mg}$ of ICG dye was injected via a peripheral vein. For visualization, the Zeiss Pentero operating microscope (Carl Zeiss $\mathrm{GmbH}$ ) with integrated near-infrared ICG angiography (IR800) was used. In cases in which parent or branching vessel stenosis or residual aneurysm necks were identified with ICG, the clip position was changed or additional clips were applied and another ICG was performed. Additionally, the clipped aneurysm dome was opened with a fine needle or with scissors in every patient to screen for incomplete clipping.

\section{RESULTS}

Results are summarized in Table 1.

\section{Sample details}

We evaluated the treatment of 61 intracranial aneurysms in 56 patients from 2009 to 2014. Forty seven patients (77\%) were female and 14 (23\%) were male. Aneurysmal sites were middle cerebral artery (MCA) in $26 \%$ of cases, carotid bifurcation (CB) in 10\%, anterior communicating artery (AcoA) in $5 \%$, pericallosal artery $(\mathrm{PA})$ in $2 \%$, posterior communicating artery (PcoA) in $5 \%$ and ophthalmic artery (OA) in $52 \%$. Eight patients presented with SAH and 53 without SAH.

Table 1. Features of treated patients.

\begin{tabular}{lcc}
\hline Aneurysmal site & Female & Male \\
\hline MCA & 11 & 5 \\
CB & 4 & 2 \\
AcoA & 2 & 1 \\
PA & 1 & 0 \\
PcoA & 3 & 0 \\
OA & 26 & 6 \\
Total & 47 & 14 \\
\hline
\end{tabular}

MCA: middle cerebral artery; CB: carotid bifurcation; AcoA: anterior communicating artery; PA: pericallosal artery; PcoA: posterior communicating artery; OA: ophthalmic artery.
Clip reposition after ICG happened in 2 patients (3.2\%). One with MCA aneurysm, due to calcified plaque and residual aneurismal filling after initial clipping (Figure 1) and other with ophthalmic artery aneurysm.

\section{Complications}

Complications due to intraoperative ICG were not encountered.

\section{DISCUSSION}

ICG is a valuable tool to assess intraoperative details

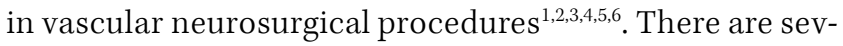
eral clinical applications (Table 2) and main advantages of ICG are the high contrast view, allowing only the target, not background, to be visible (Figure 2); the dye is confined to the vascular compartment through binding with plasma proteins; low toxicity and the rapid excretion, almost exclusively into the bile. ICG does not have any known metabolites, and it is fast extracted by the liver into bile juice $7,8,9,10,11,12,13,14,15,16,17,18,19,20,21,22,23,24$.

Neurosurgery is ideal for ICG because operations are done under an optic microscope and camera. Initial experience of ICG and vascular neurosurgery were reported by Wrobel et

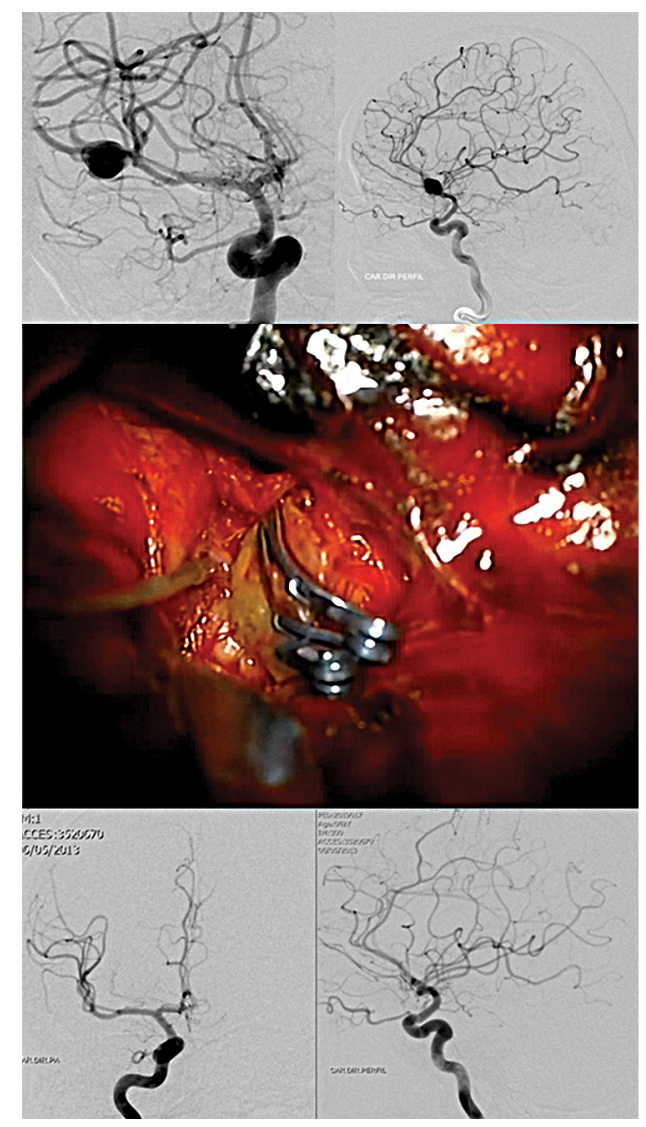

Figure 1. Pre operative (above), intraoperative (middle) and post operative (below) aspects of a middle cerebral artery aneurysm operated using indocyanine green. 
Table 2. Current clinical applications of indocyanine green.

\begin{tabular}{ll}
\hline Neurosurgery & Aneurysm surgery \\
& Arteriovenous malformation surgery \\
& Tumor surgery \\
& Peripheral nerve surgery \\
& Hydrocephalus and endoscopy \\
& Microvascular decompression surgery \\
& Aneurysm surgery \\
Vascular surgery & Peripheral vascular disease \\
Cardiothoracic surgery & Coronary surgery \\
Oncology & Sentinel lymph node harvesting \\
& Breast surgery \\
Liver surgery & Evaluation of liver blood flow \\
Laparoscopy & Laparoscopic cholecystectomy \\
Reconstrutive & Microvascular surgery \\
microsurgery & \\
Ophtalmology & Retinography \\
\hline
\end{tabular}

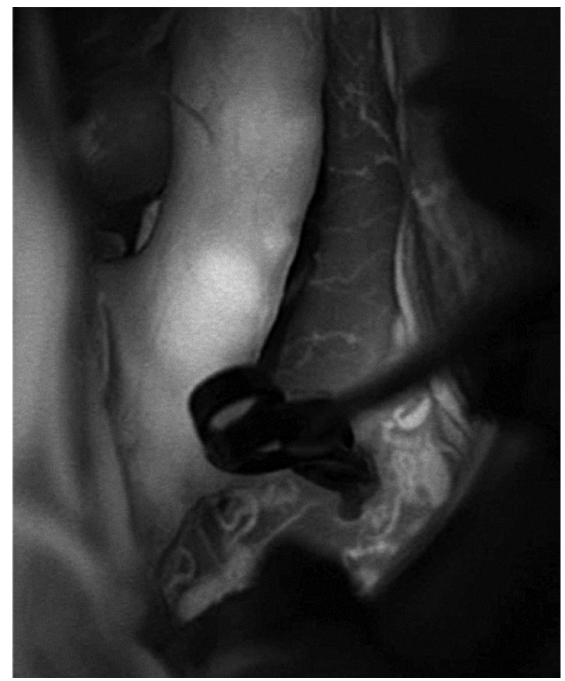

Figure 2. Intraoperative use of indocyanine green, revealing detailed images of parent vessels and perforators. al in 1994, but in 2001 it was at first used in neurosurgical microscope. In 2003, it was used in clinical neurosurgery and in 2009 a real time microscopic software was applied in neurovascular interventions ${ }^{5,23}$.

We performed neurosurgical treatment of 61 aneurysms in 56 patients in 5 years of experience. Aneurysmal sites were varied, but mainly composed of ophthalmic artery. ICG was used twice in fifty six patients. In a unique case of a MCA aneurysm ICG was used thrice, because puncturing the dome of the aneurysm after clipping revealed persistent flow within the aneurysm despite ICG showing no flow after clipping. In this case, clip was repositioned.

Generally, highly variable clip adjustment rates of $2 \%-38 \%$ following ICG have been reported since the introduction of this imaging technique. The larger report in literature until now revealed a rate of clip adjustment of $9.1 \%$ of 295 aneurysms treated in 232 patients. The variance may be attributable to a low number of patients, inhomogeneous patient groups, and the nonsystematic application of the technique in previous studies ${ }^{8,9,10,11,12,13}$.

Intraoperative conventional digital subtraction angiography (DSA) is still the gold standard measure to evaluate intracranial vasculature in pre operative, intra operative and post operative situations. Although several studies highlighted higher sensitivity of DSA compared to ICG, there is a discordance rate usually below $10 \%{ }^{14}$, making ICG a valuable, less invasive and accurate to perform clipping in the majority of cases, being DSA reserved for extraordinary situations ${ }^{14}$. In Table 3 , we present main considerations about each strategy ${ }^{14,15,16,17,18}$.

Our casuistic corroborates ICG as a practical, fast, safe, accurate and reliable option to be employed during vascular neurosurgery procedures, allowing neurosurgeon to assess the quality of surgery and to perform immediate necessary changes avoiding time consuming and complications associated with DSA.

Table 3. Peculiarities of indocyanine green and digital subtraction angiography.

\begin{tabular}{|c|c|}
\hline ICG & Digital Subtraction Angiography \\
\hline \multirow{2}{*}{$\begin{array}{l}\text { Only dissected and visible vascular structures within the operative } \\
\text { field can be evaluated }\end{array}$} & Gold standard \\
\hline & Better to visualize hidden parts of the parent, branching, and \\
\hline \multirow{2}{*}{$\begin{array}{l}\text { May be obstructed by arteriosclerotic or calcified plaques within } \\
\text { the vessel walls or simply by cisternal blood }\end{array}$} & perforator vessels as well as undissected parts of the aneurysm dome \\
\hline & Twice as sensitive \\
\hline Inexpensive & Dependent of a neurovascular team \\
\hline Easy & Additional complications (1-2\%) \\
\hline Low complications & Time consuming \\
\hline No much extra time & Limited evaluation of perforating vessels \\
\hline \multicolumn{2}{|l|}{ Excellent evaluation of perforating vessels } \\
\hline \multicolumn{2}{|l|}{ Nontoxic and nonionizing } \\
\hline \multicolumn{2}{|l|}{ No systemic metabolites } \\
\hline \multicolumn{2}{|l|}{ Short interruption of surgical action } \\
\hline \multicolumn{2}{|l|}{ Surgical manipulation during ICG-VA possible } \\
\hline \multicolumn{2}{|l|}{ Not reliable in complex aneurysm anatomy } \\
\hline \multicolumn{2}{|l|}{ No 3D reconstruction available } \\
\hline False-negative assessment possible & \\
\hline
\end{tabular}

ICG-VA: indocyanine green video angiography. 
Some limitations should be characterized. At first, the number of patients treated were not as large as previous reports in literature. Then, as focused before, 25 out of 60 patients treated were submitted to ophthalmic artery clipping. We did not apply routine intraoperative digital subtraction angiography, once we believe it is time consuming and adds potential risks to surgery. Finally, ICG is a simple and safe procedure and an important adjunct to microsurgical clipping of aneurysm. Although it assesses vessel patency and obliteration of aneurysms in most cases, applying the principles of microsurgery in aneurysm clipping remains a main tool for obtaining the complete obliteration of aneurysm along with preservation of the normal vasculature.
In conclusion, the application of ICG in vascular neurosurgery is still an emerging challenge. Current trends point to higher success rates in clipping procedures and fewer aneurismal remnants. It is an adjunctive strategy which facilitates aneurismal evaluation and treatment in experienced hands. Nevertheless, a qualified vascular neurosurgeon is still the most important component of a high quality work.

Intraoperative angiography remains the gold standard method to analyse cerebral vasculature and there is still need to determine clearly the threshold for indicating one method over the other.

\section{References}

1. Zaidi HA, Abla AA, Nakaji P, Chowdhry SA, Albuquerque FC, Spetzler RF. Indocyanine green angiography in the surgical management of cerebral arteriovenous malformations: lessons learned in 130 consecutive cases. Neurosurgery. 2014;10 Suppl 2:246-51. http://dx.doi.org/10.1227/NEU.0000000000000318

2. Mielke D, Malinova V, Rohde V. Comparison of intraoperative microscopic and endoscopic ICG angiography in aneurysm surgery. Neurosurgery. 2014:10 Suppl 3:418-25. http://dx.doi.org/10.1227/NEU.0000000000000345

3. Zhang H, Fu WM, Chen P, Shi J. Intraoperative indocyanine green angiography during microvascular decompression surgery: report of 30 cases. Acta Neurochir (Wien). 2014;156(8):1561-4. http://dx.doi.org/10.1007/s00701-014-2105-x

4. Scerrati A, Della Pepa GM, Conforti G, Sabatino G, Puca A, Albanese A et al. Indocyanine green video-angiography in neurosurgery: a glance beyond vascular applications. Clin Neurol Neurosurg. 2014;124:106-13. http://dx.doi.org/101016/j.clineuro.2014.06.032

5. Raabe A, Beck J, Gerlach R, Zimmermann M, Seifert V. Near-infrared indocyanine green video angiography: a new method for intraoperative assessment of vascular flow. Neurosurgery. 2003;52(1):132-9.

6. Özgiray E, Aktüre E, Patel N, Baggott C, Bozkurt M, Niemann D et al. How reliable and accurate is indocyanine green video angiography in the evaluation of aneurysm obliteration? Clin Neurol Neurosurg. 2013;115(7):870-8. http://dx.doi.org/10.1016/j.clineuro.2012.08.027

7. Wachter D, Behm T, Eckardstein K, Rohde V. Indocyanine green angiography in endoscopic third ventriculostomy. Neurosurgery. 2013;73(1 Suppl Operative):ons67-72; ons72-3. http://dx.doi.org/10.1227/NEU.0b013e318285b846

8. Jiang H, Ni W, Xu B, Lei Y, Tian Y, Xu F et al. Outcome in adult patients with hemorrhagic moyamoya disease after combined extracranial-intracranial bypass. J Neurosurg. 2014;121(5):1048-55. http://dx.doi.org/10.3171/2014.7.JNS132434

9. Alander JT, Kaartinen I, Laakso A, Pätilä T, Spillmann T, Tuchin VV et al. A review of indocyanine green fluorescent imaging in surgery. Int J Biomed Imaging. 2012;2012:ID940585. http://dx.doi.org/10.1155/2012/940585

10. Dashti R, Laakso A, Niemelä M, Porras M, Hernesniemi J. Microscopeintegrated near-infrared indocyanine green videoangiography during surgery of intracranial aneurysms: the Helsinki experience. Surg Neurol. 2009;71(5):543-50. http://dx.doi.org/10.1016/j.surneu.2009.01.027

11. David CA, Vishteh AG, Spetzler RF, Lemole M, Lawton MT, Partovi S. Late angiographic follow-up review of surgically treated aneurysms. J Neurosurg. 1999;91(3):396-401. http://dx.doi.org/10.3171/jns.1999.91.3.0396

12. Feindel W, Yamamoto YL, Hodge CP. Intracarotid fluorescein angiography: a new method for examination of the epicerebral circulation in man. Can Med Assoc J. 1967;96(1):1-7.

13. Feuerberg I, Lindquist C, Lindqvist M, Steiner L. Natural history of postoperative aneurysm rests. J Neurosurg. 1987;66(1):30-4. http://dx.doi.org/10.3171/jns.1987.66.1.0030
14. Fischer G, Stadie A, Oertel JM. Near-infrared indocyanine green videoangiography versus microvascular Doppler sonography in aneurysm surgery. Acta Neurochir (Wien). 2010;152(9):1519-25. http://dx.doi.org/10.1007/s00701-010-0723-5

15. Morcos JJ. Editorial: indocyanine green videoangiography or intraoperative angiography? J Neurosurg. 2013;118(2):417-8. http://dx.doi.org/10.3171/2012.6.JNS1285

16. Gruber A, Dorfer C, Bavinzski G, Standhardt H, Ferraz-Leite H, Knosp E. Superselective indocyanine green angiography for selective revascularization in the management of peripheral cerebral aneurysms. AJNR Am J Neuroradiol. 2012;33(3):E36-7. http://dx.doi.org/10.3174/ajnr.A2424

17. Gruber A, Dorfer C, Standhardt H, Bavinzski G, Knosp E. Prospective comparison of intraoperative vascular monitoring technologies during cerebral aneurysm surgery. Neurosurgery. 2011;68(3):657-73. http://dx.doi.org/10.1227/NEU.0b013e31820777ee

18. Imizu S, Kato Y, Sangli A, Oguri D, Sano H. Assessment of incomplete clipping of aneurysms intraoperatively by a near-infrared indocyanine green-video angiography (Niicg-Va) integrated microscope. Minim Invasive Neurosurg. 2008;51(4):199-203. http://dx.doi.org/10.1055/s-2008-1080916

19. Jing Z, Ou S, Ban Y, Tong Z, Wang Y. Intraoperative assessment of anterior circulation aneurysms using the indocyanine green video angiography technique. J Clin Neurosci. 2010;17(1):26-8. http://dx.doi.org/10.1016/j.jocn.2009.03.034

20. Kim DL, Cohen-Gadol AA. Indocyanine-green videoangiogram to assess collateral circulation before arterial sacrifice for management of complex vascular and neoplastic lesions: technical note. World Neurosurg. 2013;79(2):404.e1-4.e6. http://dx.doi.org/10.1016/j.wneu.2012.07.028

21. Li J, Lan Z, He M, You C. Assessment of microscope-integrated indocyanine green angiography during intracranial aneurysm surgery: a retrospective study of 120 patients. Neurol India. 2009;57(4):453-9. http://dx.doi.org/10.4103/0028-3886.55607

22. Murai Y, Adachi K, Takagi R, Koketsu K, Matano F, Teramoto A. Intraoperative Matas test using microscope-integrated intraoperative indocyanine green videoangiography with temporary unilateral occlusion of the A1 segment of the anterior cerebral artery. World Neurosurg. 2011;76:477.e7-10. http://dx.doi.org/10.1016/j.wneu.2011.03.044

23. Washington CW, Zipfel GJ, Chicoine MR, Derdeyn CP, Rich KM, Moran $\mathrm{CJ}$, et al. Comparing indocyanine green videoangiography to the gold standard of intraoperative digital subtraction angiography used in aneurysm surgery. J Neurosurg. 2013;118(2):420-7. http://dx.doi.org/10.3171/2012.10.JNS11818

24. Wrobel CJ, Meltzer H, Lamond R, Alksne JF. Intraoperative assessment of aneurysm clip placement by intravenous fluorescein angiography. Neurosurgery. 1994;35(5):970-3. 